\title{
DADOS Rb-Sr E Sm-Nd DA REGIÃO DE JUSSARA-GOIÁS-MOSSÂMEDES (GO), E O LIMITE ENTRE TERRENOS ANTIGOS DO MACIÇO DE GOIÁS E O ARCO MAGMÁTICO DE GOIÁS.
}

\author{
MÁRCIO MARTINS PIMENTEL, REINHARDT A. FUCK \& LUIZ J. H. DEL'REY SILVA
}

\begin{abstract}
Rb-Sr AND Sm-Nd DATA FROM THE JUSSARA-GOIÁS-MOSSÂMEDES REGION (GO, BRAZIL) AND THE LIMIT BETWEEN ANCIENT TERRANES OF THE GOIAS MASSIF AND THE GOIÁS MAGMATIC ARC The nature of the limits between the Archean/Paleoproterozoic terrains of the Goiás Massif and the Neoproterozoic (ca. 900 - 650 Ma) juvenile terrains of the Goiás Magmatic Are is still poorly understood. In this study we have investigated southwestern and southern áreas of the massif, in the region between the towns of Goiás, Jussara and Mossâmedcs. Several granitic, gneissic and mylonitic rock were recognized and dated $(\mathrm{Rb}-\mathrm{Sr}$ and Sm-Nd methods) units in the transect between Goiás, situated in the Goiás Massif and Jussara, in the magmatic are. From east to west they are: (i) Uvá tonalitic gneiss (GT) $\left(2564 \pm 140 \mathrm{Ma}\right.$; i.r. $=0.7017 \pm 0.0003 ; \mathrm{T}_{\mathrm{DM}}=3.0-3.5$ $\mathrm{Ga})$; (ii) Uvá granite $(\mathrm{GU})\left(2851 \pm 180 \mathrm{Ma} ; \varepsilon_{\mathrm{Nd}}(\mathrm{T})=+0.3 ; \mathrm{T}_{\mathrm{DM}}=3.0-3.1 \mathrm{Ga}\right)$; (iii) Itapirapuã mylonitic gneiss; (GMI) (iv) syn-tectonic coarse-grained porphyritic granite $(\mathrm{GPG})\left(759 \pm 62 \mathrm{Ma}\right.$; i.r. $\left.=0.7053 \pm 0.0002 ; \mathrm{T}_{\mathrm{DM}}=2.0-2.3 \mathrm{Ga}\right)$; (v) Granitic gneiss (GG) $\left(2601 \pm 209\right.$ Ma; i.r. $\left.=0.7016 \pm 0.0007 ; \mathrm{T}_{\mathrm{DM}}=2.4-2.5 \mathrm{Ga}\right)$, (vi) Mylonitic gneiss $(\mathrm{GM})$. GT and GU display predominantly E-W tectonic foliation, with a local and weak superimposed N-S deformation. N-S structures become progressively more important towards the west, with the development of wide dextral shear zones, which are typical in the rocks of the magmatic are. The structural and geochronologic data indicate that the E-W deformational fabric is Archaean or Paleoproterozoic in age, and the N-S fabric is Neoproterozoic. Felsic metavolcanic rocks from the Mossâmedes área, soutlvof the Goiás Archaean terrains, yielded Rb-Sr isochron ages of $1978 \pm 55 \mathrm{Ma}$ and $1582 \pm 101 \mathrm{Ma}$, with initial ${ }^{87} \mathrm{Sr} /{ }^{86} \mathrm{Sr}$ ratios of ca. 0.7023 and 0.7053 , respectively. Therefore, these rocks are not part of the Neoproterozoic magmatic are, and are better interpreted as part of the southern edge of the Goiás Massif. The data presented suggest that the rocks investigated here are part of the southern and southwestern edges of the São Francisco-Congo continental plate. According to this reconstruction the Goiás massif represented an indentation of that plate during the continental collision that originated the Brasília Belt.
\end{abstract}

Keywords: Brasiliano Cycle, paleogeography, Neoproterozoic, continental collision, indentation.

RESUMO A natureza dos limites entre os terrenos arqueanos/paleoproterozóicos do Macico de Goiás e os terrenos juvenis neoproterozóicos (ca. 900 a $650 \mathrm{Ma}$ ) do chamado Arco Magmático de Goiás é ainda mal entendida. Neste trabalho foram investigados os limites sudoeste e sul do maciço, na região compreendida entre as cidades de Goiás, Jussara e Mossâmedes. Em uma transversal E-W entre Goiás, situada no Maciço de Goiás, e Jussara, localizada no arco magmático, foram identificadas e datadas (métodos $\mathrm{Rb}-\mathrm{Sr}$ e $\mathrm{Sm}-\mathrm{Nd}$ ) as seguintes unidades de rochas graníticas, gnáissicas e miloníticas: (i) gnaisse tonalítico de Uvá (GT) $\left(2564 \pm 140 \mathrm{Ma}, \mathrm{r} . \mathrm{i}=0.7017, \mathrm{~T}_{\mathrm{DM}}=3.0-3.5 \mathrm{Ga}\right)$; (ii) granito Uvá $(\mathrm{GU})\left(2851 \pm 180 \mathrm{Ma}, \varepsilon_{\mathrm{Nd}}(\mathrm{T})=+0.3, \mathrm{~T}_{\mathrm{DM}}=3.0-3\right.$. $\left.1 \mathrm{Ga}\right)$; (iii) gnaisse milonítico de Itapirapuã (GMI); (iv) granito porfirítico grosso $(\mathrm{GPG})\left(759 \pm 62 \mathrm{Ma}\right.$, r.i. $\left.=0.7053, \mathrm{~T}_{\mathrm{DM}}=2.0-2.3 \mathrm{Ga}\right) ;(\mathrm{v})$ gnaisse granítico $(\mathrm{GG})(2601 \pm$ $209 \mathrm{Ma}$, r.i. $\left.=0.7016, \mathrm{~T}_{\mathrm{DM}}=2.4-2.5 \mathrm{Ga}\right) \mathrm{e}(\mathrm{vi})$ gnaisse milonítico $(\mathrm{GM})$.

As unidades GT e GU mostram foiiação tectônica em torno de E-W, com mergulhos para norte, a qual é fracamente afetada por uma deformação superimposta de direção aproximada N-S. Em direcão a oeste, estruturas de direcão N-S tornam-se progressivamente mais importantes, com o desenvolvimento de importantes zonas de cisalhamento dextrais, característica deformação impressa nas rochas do arco magmático. Os dados geocronológicos e estruturais permitem atribuir a deformação E-W ao Arqueano ou Paleoproterozóico e a N-S ao Neoproterozóico. Rochas metavulcânicas félsicas da região de Mossâmedes, a sul dos terrenos arqueanos de Goiás, forneceram idades isocrônicas $\mathrm{Rb}-\mathrm{Sr}$ de $1978 \pm 55 \mathrm{Ma}$ e $1582 \pm 101 \mathrm{Ma}$, com razões ${ }^{87} \mathrm{Sr} r{ }^{X 6} \mathrm{Sr}$ iniciais de ca. 0.7023 e 0.7053 , respectivamente. Elas não integram, portanto, o arco magmático neoproterozóico e são aqui interpretadas como componentes da borda sul do maciço. Os dados permitem sugerir uma reconstrução paleogeográfica neoproterozóica segundo a qual as rochas estudadas integram a borda sudoeste-sul da placa do São Francisco-Congo e o Maciço de Goiás representa uma saliência indentadora durante a colisão continental que originou a Faixa Brasília.

Palavras-Chave: Ciclo Brasiliano, paleogeografia, colisão continental, indentação, Neoproterozóico.

INTRODUÇ̃̃O Em trabalhos recentes, o Arco Magmático de Goiás (Fig. 1) tem sido apontado como uma das principais unidades geotectônicas da Província Tocantins (Pimentel \& Fuck 1992, Fuck et al. 1994). Dados isotópicos, geocronológicos e geoquímicos em diversas unidades de rochas metavulcânicas e granitóides das regiões de Arenópolis e Mara Rosa, respectivamente no oeste e noroeste de Goiás, têm demonstrado que os protólitos originais dessas unidades metamórficas se formaram em ambientes de arco magmático entre ca.900e600Ma(Pimentel\&Fuck 1992,Pimenteira/. 1992 , 1994,1996, Viana 1995, Rodrigues \&Pimentel 1995). Muito embora os dados geocronológicos e isotópicos tenham se mostrado consistentes, os limites geográficos do Arco Magmático de Goiás e a natureza das suas relações com as unidades geotectônicas vizinhas ainda são mal conhecidos e dependem de mais estudos geocronológieos e estruturais em áreas chave. Neste trabalho são apresentados dados geocronológicos e isotópicos $\mathrm{Rb}$-Sr e Sm-Nd inéditos, para unidades de rochas ortognáissicas, metavulcânicas e graníticas expostas na região compreendida aproximadamente entre as cidades de Goiás, Jussara e Mossâmedes (Figs 1 e 2). Os estudos realizados acrescem dados que permitem definir mais precisamente a forma e a natureza do limite entre os terrenos antigos da porção sul do Maciço de Goiás e os terrenos neoproterozóicos do arco magmático expostos mais a oeste e sul do maciço.

GEOLOGIA REGIONAL A porção oriental da Província Tocantins configura um sistema de dobramentos neoproterozóicos desenvolvido ao longo do flanco ocidental do Cráton do São Francisco (Fig. 1). Nessa região são identificados os seguintes compartimentos geotectônicos (Fuck et al 1994):

Cráton do São Francisco - caracterizado por extensas coberturas sedimentares sub-horizontais ou levemente deformadas (Grupos Bambuí e Paranoá) e seu embasamento granito-gnáissico arqueano e paleoproterozóico; 


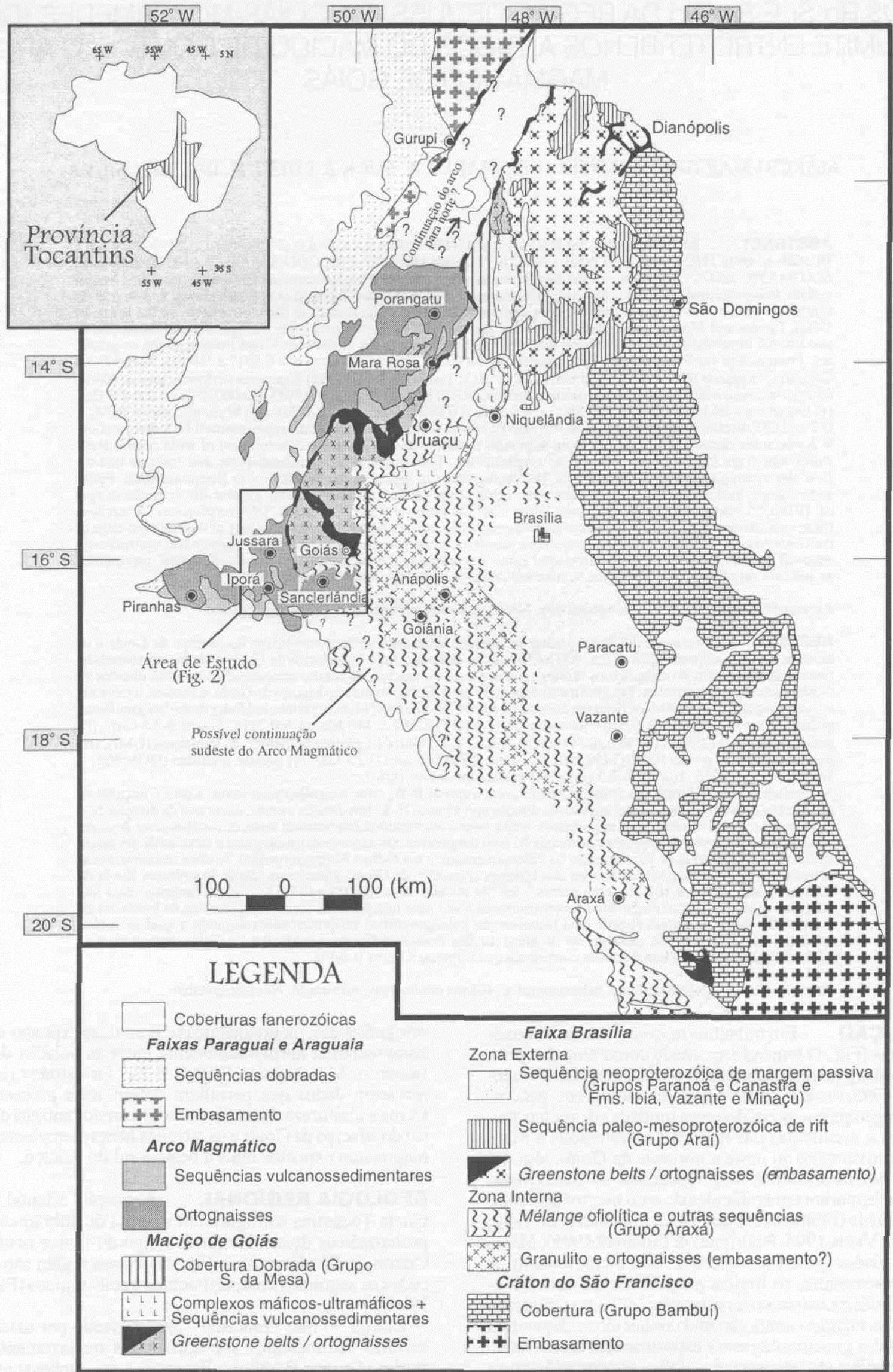

Figura 1 - Mapa regional mostrando as principais unidades geotectônicas da porção leste da Província Tocantins (modificado de Fuck et al, 1994)

Figure 1 - Regional map showing the main geotectonic units of the eastern part of the Tocantins Province (modified from Fuck et al., 1994) 
Faixa Brasília - subdividida nas zonas externa e interna. $\mathrm{Na}$ sua zona externa é formada pêlos metassedimentos plataformais dos grupos Paranoá e Canastra e formações Vazante, Ibiá e Minaçu, bem como por porções do seu embasamento. A zona interna inclui unidades alóctones de micaxistos e rochas associadas (Grupo Araxá) e áreas do seu embasamento. Os micaxistos são derivados de sedimentos turbidíticos aos quais se associam sedimentos químicos e variada contribuição de origem vulcânica, além de mélanges ofiolíticas;

Maciço de Goiás - inclui terrenos arqueanos e paleoproterozóicos da porção central da Província Tocantins. De acordo com Fuck et al. (1994), o maciço representa um fragmento crustal muito complexo, de significado tectônico mal conhecido, já tendo sido interpretado como um alto do embasamento antigo ou como uma microplaca envolvida na orogênese Brasiliana;

Arco Magmático de Goiás - engloba sequências vulcanosedimentares e rochas granitóides associadas, com assinaturas geoquímica e isotópica características de arcos vulcânicos. Está bem exposto na região oeste de Goiás, entre Sanclerlândia e Bom Jardim de Goiás, de onde se estende para norte, até a região de Mara Rosa-Porangatu, no noroeste de Goiás. Trata-se de crosta juvenil formada entre ca. 900 e 600 Ma (Pimentel \& Fuck 1992, Pimentel et al 1994, 1996). Os limites geográficos do arco ainda não são conhecidos com precisão, em função da falta de dados geocronológicos e estruturais.

A área deste estudo (Fig. 1) está localizada na porção centro-sul da Província Tocantins, na região sul do Maciço de Goiás, onde esta unidade geotectônica se defronta com o Arco Magmático de Goiás (Figs le 2).
GEOLOGIA DA ÁREA O mapa geológico simplificado da Fig. 2 mostra as principais unidades geológicas expostas na região compreendida entre as cidades de Goiás, Jussara e Mossâmedes. O conhecimento geológico desta região é baseado em trabalhos em escalas muito variadas.

Os terrenos gnáissicos expostos a oeste do greenstone belt de Goiás, entre as cidades de Goiás e Jussara, são conhecidos apenas superficialmente. Por outro lado, as rochas metassedimentares que sustentam a Serra Dourada (Fig. 2), bem como as unidades de rochas metavulcânicas e metassedimentares a sul da serra, são conhecidas em maior detalhe, especialmente em função dos trabalhos de Danni et al. (1973), Dardenne et al (1981), Simões (1984) e Barbosa \& Jost (1990).

Nos terrenos granito-gnáissicos expostos ao norte da Serra Dourada, afloram gnaisses tonalíticos, milonitos, granitos e granodioritos deformados, bem como migmatitos locais, aparentemente configurando típicos terrenos TTG arqueanos. Entretanto, as relações entre os diversos tipos litológicos são desconhecidas. Ao longo da transversa entre as cidades de Goiás e Jussara, foram identificadas as seguintes unidades geológicas (Figs. 3 e 4): (i) Gnaisses tonalíticos (GT) de granulação grossa, ricos em biotita e hornblenda; (ii) Granito Uvá (GU), caracteristicamente leucocrático, de granulação média, foliado e contendo biotita. As relações geológicas com os GT não foram observadas; (iii) Gnaisses miloníticos (GMI) de granulação fina, com intercalações de micaxistos. Ocorrem nas vizinhanças de Itapirapuã, normalmente intemperizados e muito mal expostos; (iv) Granito porfirítico grosso (GPG), com megacristais de feldspato de até $15 \mathrm{~cm}$ de comprimento. É sintectônico ao ciclo Brasiliano, como se discute adiante

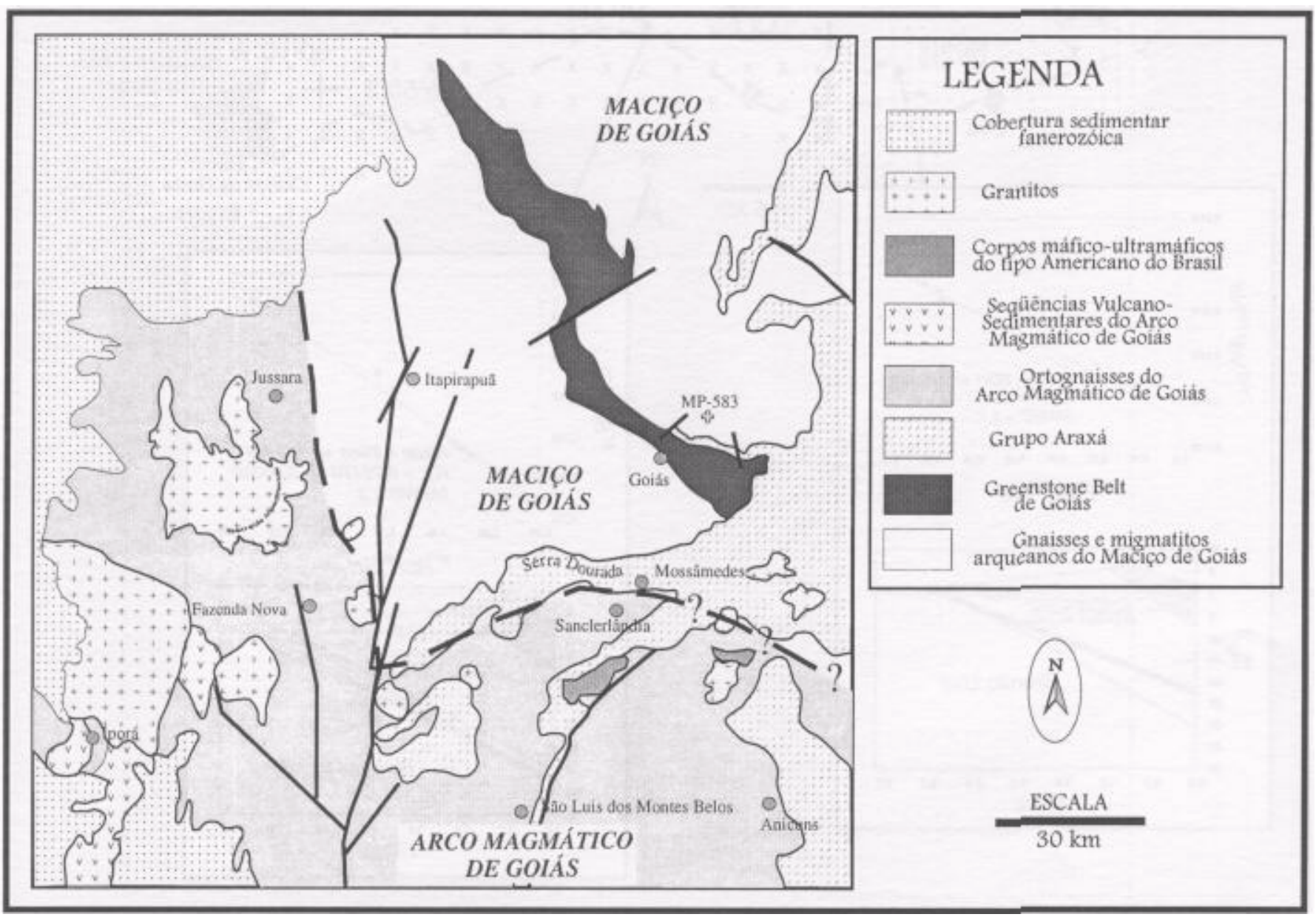

Figura 2 - Mapa geológico esquemático da região de Goiás-Jussara-Mossâmedes.

Figure 2 - Geological sketch map of the Goiás-Jussara-Mossâmedes region. 
neste trabalho; (v) Granito-gnaisse (GG) igualmente porfirítico, porém de granulação mais fina, com foliação e bandamento mais evidentes que o GPG; (vi) Gnaisses miloníticos (GM), mal expostos e intemperizados como os de Itapirapuã, com passagens de gnaisses bandados de granulação fina a média e intercalações de micaxistos; (vii) Hornblenda granito (HG), que ocorre nas cercanias de Jussara (Fig. 4), sendo de granulação média, equigranular, levemente deformado, contendo xenólitos abundantes de rochas gnáissicas e de anfibolitos, provavelmente integrante do Arco Magmático de Goiás. Os dados estruturais coletados ao longo da transversa Goiás-Jussara, ainda que não sejam abundantes, indicam claramente a crescente importância de deformação N-S sobre estruturas E-W, à medida que se avança para oeste, em direção ao arco magmático (Figs. 3 e 4). O bandamento gnáissico do GT a oeste de Goiás é afetado por dobras isoclinais de escala sub-métrica com eixo caindo suavemente para ENE e tendo foliação plano axial marcada preferencialmente por biotita, a mesma impressa em granitos da região de Uvá. No trecho Goiás-Uvá, bandamento e foliação mostram direções que variam de $\mathrm{N} 70^{\circ} \mathrm{E}$ a $\mathrm{N} 50^{\circ} \mathrm{W}$ mergulhando de $50^{\circ}-70^{\circ}$ para norte, sugerindo que dobras abertas, com plano axial N-S e de grande comprimento de onda, arqueiam suavemente um conjunto granito-gnáissico previamente deformado. Esse padrão se mantém até cerca de $17 \mathrm{~km}$ a oeste de Uvá, onde ocorre a zona de cisalhamento Uvá-Caiçaras, com direção geral $\mathrm{N} 40^{\circ} \mathrm{E}$ e mergulho subvertical, com pelo menos 20 metros de largura aflorante em corte na estrada, onde estão expostos ultramilonitos quartzosos de cor branca amarelada, no domínio dos gnaisses miloníticos (GM; Fig.4). Indicadores cinemáticos $\mathrm{S}-\mathrm{C}$ e lineação de estiramento em ribbons de quartzo $\left(09^{\circ} / 030^{\circ}\right)$ indicam movimento transcorrente dextral. Essa zona de cisalhamento tem aparente continuidade no lineamento de Messianópolis-Novo Brasil (Jost et al. 1986) aproximadamente paralelo à zona de cisalhamento (Fig. 2), onde gnaisses milonitizados forneceram idade $\mathrm{Rb}-\mathrm{Sr}$ isocrônica de ca. de $600 \mathrm{Ma}$ (Pimentel et al. 1991).

Daí para oeste, especialmente a partir de Itapirapuã, predominam atitudes variando de $\mathrm{N} 20^{\circ} \mathrm{E}$ a $\mathrm{N} 20^{\circ} \mathrm{W}$, com mergulhos de $30^{\circ}$ a $80^{\circ}$ para $\mathrm{W}$, ou mesmo sub-verticais. No limite do arco magmático, cerca de $7 \mathrm{~km}$ a leste de Jussara (Fig. 4), os gnaisses ocorrem afetados por um conjunto de dobras apertadas a isoclinais, com assimetria $\mathrm{S}$ em superfície, em escalas de $10 \mathrm{~cm}$ a $1 \mathrm{~m}$, associadas a foliação plano axial penetrativa marcada por quartzo e biotita (atitude $\mathrm{N} 16^{\circ} \mathrm{E} / 80^{\circ} \mathrm{W}$ ) e tendo eixos caindo suavemente para norte $\left(12^{\circ} / 014^{\circ}\right)$. Semelhantes atitudes de foliação plano axial e eixos de dobras são observados a sul e sudeste de Jussara, na

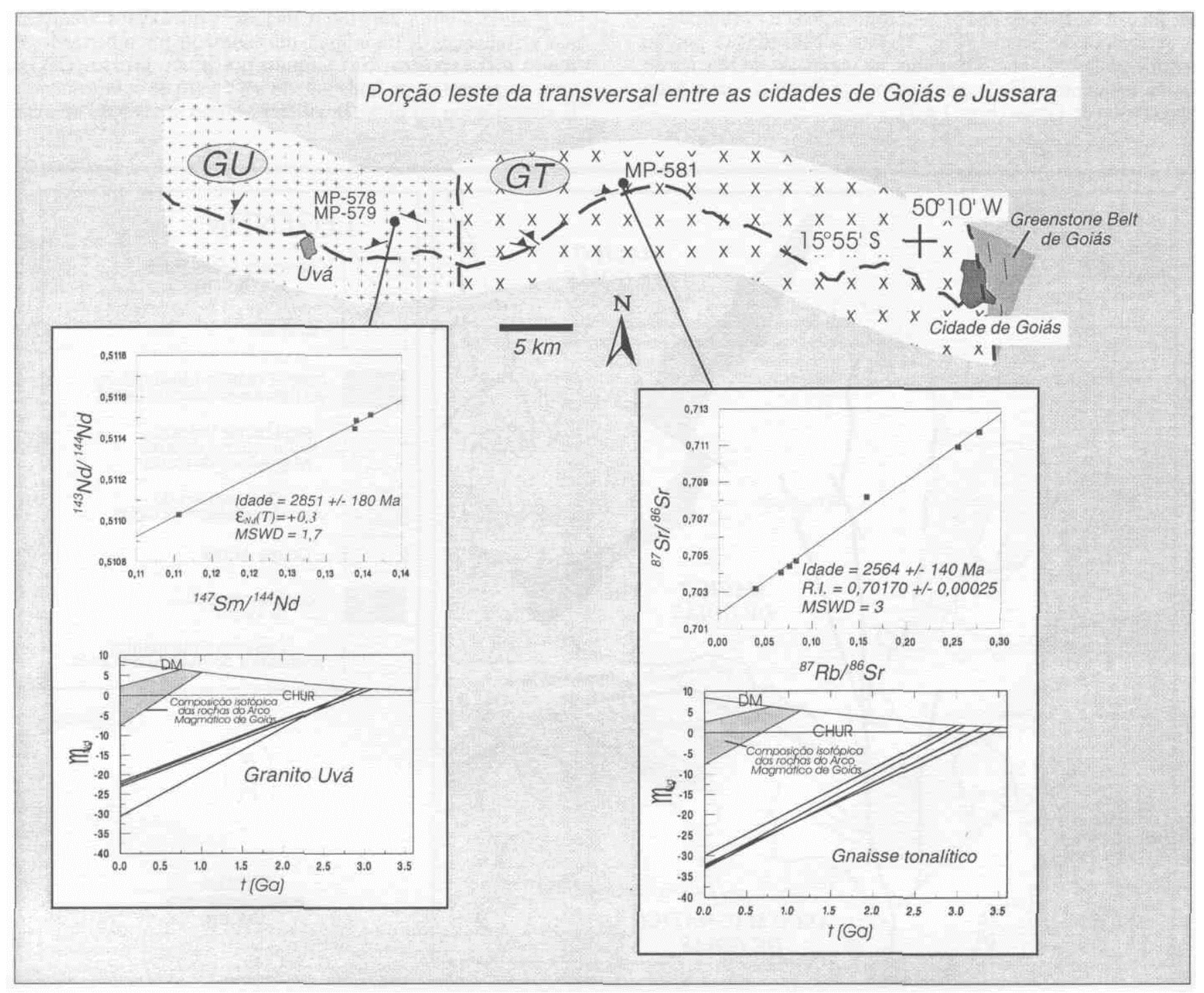

Figura 3 - Porção leste da transversal entre as cidades de Goiás e Jussara. GT- gnaisse tonalítico de Uvá; GU - granito Uvá. Figure 3 - Eastern part of the transect between the towns of Goiás and Jussara. GT - Uvá tonalitic gneiss; GU - Uvá granite 
estrada para Fazenda Nova, região onde predominam zonas de cisalhamento de direções sub-meridianas (Fig. 2).

Dentre estas vale destacar a zona de cisalhamento que aflora amplamente na borda leste do Serra do Impertinente, especialmente ao longo do Córrego do Boqueirão, e que tem expressão em mapa por mais de $60 \mathrm{~km}$ na direção geral norte-sul. Na localidade em questão, a zona de falha constitui-se de clorita-quartzo milonitos e ultramilonitos com direção $\mathrm{N} 18^{\circ} \mathrm{W}$ e mergulho subvertical, tratando-se claramente de transcorrência dextral, conforme indicam a lineação de estiramento sub-horizontal, as relações S-C e a consistência na assimetria $\mathrm{Z}$ de várias dobras de escala decimétrica que afetam o conjunto altamente anisotrópico.

As estruturas N-S ao longo da transversa Goiás-Jussara podem ser interpretadas como devidas ao evento Brasiliano, em face a inequívocos dados estruturais e geocronológicos encontrados em afloramentos dos graníticos porfiríticos gros- sos (GPG), em lajedo de dimensões decamétricas, situado 200 metros a sul da estrada, cerca de $7 \mathrm{~km}$ a oeste de Itapirapuã (Fig. 4). O GPG ali aflorante tem foliação magmática bem marcada por cristais euédricos, às vezes zonados, de feldspatos, com até $15 \mathrm{~cm}$ de comprimento, porém em perfeita continuidade espacial com a foliação tectônica marcada por biotita (Fig. 5). A foliação tectônica atravessa igualmente um dique subvertical de granito equigranular de direção aproximada $\mathrm{N} 20^{\circ}-30^{\circ} \mathrm{E}$, sendo defletida nas bordas internas do mesmo.

O conjunto de dados forma um quadro compatível com tensões associadas a cisalhamentos transcorrentes dextrais, apontando claramente para a contemporaneidade entre eventos de intrusão, deformação e metamorfismo, situação já descrita na literatura em outras partes do mundo, a exemplo do Proterozóico do Arizona, USA (Karlstrom \& Williams 1995).

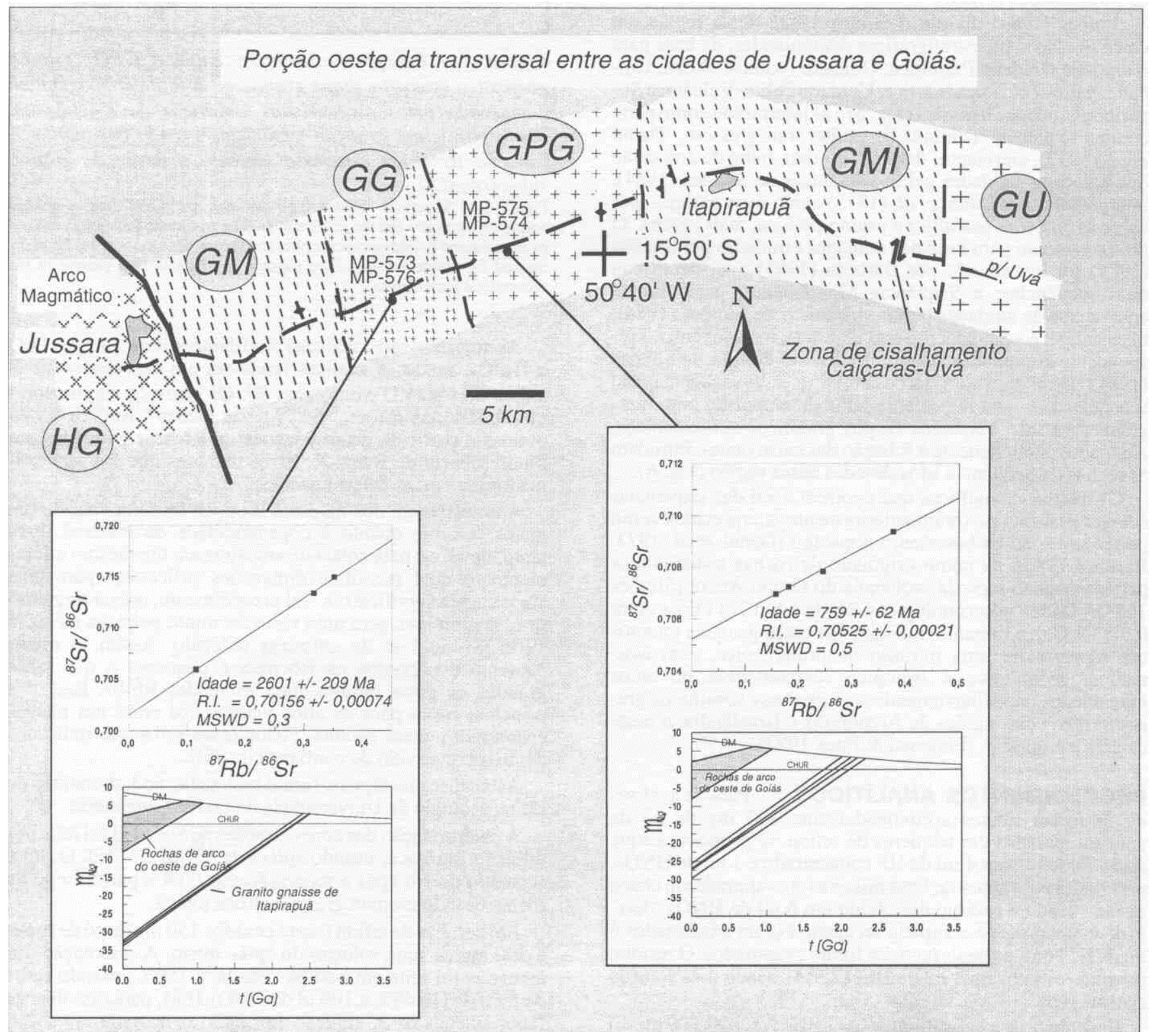

Figura 4 - Porção oeste da transversal entre as cidades de Goiás e Jussara. GU - granito Uvá; GMI - gnaisse milonítico de Itapirapuã; $G P G$ - granito porfirítico grosso; $G G$-gnaisse granítico; $G M$ - gnaisse milonítico; HG - hornblenda granito. Figure 4 - Western part of the transect between the towns of Goiás and Jussara. GU-Uvá granite; GMI- Itapirapuã mylonitic gneiss; GPG - coarse-grained porphyritic granite; GG - granitic gneiss; GM - mylonitic gneiss; HG - hornblende granite. 
Dados geocronológicos existentes para essas rochas gnáissicas e miloníticas expostas entre Goiás e Jussara são escassos. Um diagrama isocrônico $\mathrm{Rb}-\mathrm{Sr}$ de referência para gnaisses da região de Itapirapuã indica uma idade de ca. $2650 \mathrm{Ma}$, com baixa razão inicial ${ }^{87} \mathrm{Sr}{ }^{86} \mathrm{Sr}$ (ca. 0,700) (Tassinari et al., 1981). Idade K-Ar em muscovita de rocha gnáissica arqueana exposta nas vizinhanças da cidade de Goiás mostra idade de ca. $1200 \mathrm{Ma}$, sugerindo perda parcial de Ar durante o evento Brasiliano (Hasui \& Almeida, 1970).

Discordantemente sobre esses terrenos gnáissicos, repousa a sequência de rochas supracrustais expostas em direção aproximada leste-oeste, incluindo a Serra Dourada e áreas a sul desta (Fig. 2). Essa sequência é composta dominantemente por quartzitos, micaxistos e gnaisses e tem sido tradicionalmente atribuída ao Grupo Araxá (Danni et al. 1973, Dardenne et al, 1981, Simões 1984). A estratigrafia, deformação e metamorfismo dessas rochas foram estudadas em detalhe por Simões (1984) e Barbosa (1985) nas vizinhanças de Mossâmedes (Fig. 6).

Simões (1984) dividiu o Grupo Araxá dessa região em cinco unidades litoestratigráficas denominadas, da base para o topo, de Unidade Psamítica, Unidade Psamo-Pelítica, Unidade Pelito-Vulcânica Inferior, Unidade Pelito-Vulcânica Superior e Unidade Gnáissica (Fig. 6) e as interpretou como parte de uma sequência contínua de caráter transgressivo. Danni et al. (1973), entretanto, descrevem uma falha de empurrão que coloca as unidades pelito-vulcânicas de Simões (1984), interpretadas por Danni et al. (1973) como mais antigas, por sobre as unidades psamíticae psamo-pelítica, mais jovens. $\mathrm{O}$ prolongamento para leste das unidades estudadas por Simões (1984) foi investigado por Barbosa (1985) que identificou duas sequências: a Sequência Mossâmedes, parcialmente equivalente às unidades pelito-vulcânicas de Simões (1984), mais antiga, e a Sequência Serra Dourada, mais jovem, correspondente às unidades Psamítica e Psamo-Pelítica de Simões (1984). De acordo com Barbosa (1985), essas sequências são separadas por uma importante falha de empurrão com mergulho para sul. Pequenos corpos graníticos sin-tectônicos, alongados paralelamente à foliação das encaixantes, intrudem as rochas da Sequência Mossâmedes nessa região (Fig. 6).

Os gnaisses tonalíticos que ocorrem a sul das sequências supracrustais acima foram anteriormente interpretados como pertencentes ao embasamento arqueano (Danni et al 1973, Barbosa 1985), ou como originado de rochas sedimentares pertencentes ao topo da sequência do Grupo Araxá (Simões 1984). Dados geocronológicos Rb-Sr e Sm-Nd (ToM entre $0,9$ e $1,1 \mathrm{Ga})$, entretanto, indicam que esses gnaisses tonalíticos representam uma intrusão neoproterozóica, com assinaturas geoquímica e isotópica características de arcos magmáticos, semelhantemente aos gnaisses tonalíticos/granodioríticos das regiões de Arenópolis e Israelândia, a oeste da área em questão (Pimentel \& Fuck 1992).

PROCEDIMENTOS ANALÍTICOS Para as análises de $\mathrm{Sr}$ foram usados aproximadamente $200 \mathrm{mg}$ de pó da amostra, pesados em béqueres de teflon. $\mathrm{O}$ primeiro ataque ácido foi feito com $4 \mathrm{ml}$ de $\mathrm{HF}$ concentrado e $1 \mathrm{ml}$ de $\mathrm{HNO}_{3}$, para dissolver a amostra. Essa mistura foi evaporada em chapa quente, sendo o resíduo dissolvido em $6 \mathrm{ml}$ de HNOs, deixando evaporar até a completa secagem. Foram adicionados 6 $\mathrm{ml}$ de $\mathrm{HC1} 6 \mathrm{M}$, os quais também foram evaporados. O resíduo foi então diluído em $3 \mathrm{ml}$ de $\mathrm{HC} 1(2,5 \mathrm{M})$, sendo essa solução centrifugada.

Em coluna de troca catiônica (AG 50W X8,200-400 mesh) equilibrada com HC1 2,5M, é colocado $1 \mathrm{ml}$ da solução centrifugada. A coluna é lavada com $37 \mathrm{ml}$ de $\mathrm{HCl}$ 2,5M, os quais são desprezados. São passados pela coluna, então, $15 \mathrm{ml}$ do mesmo ácido, que são coletados em béqueres de teflon. Essa solução é levada para secar, obtendo-se o sal de Sr.

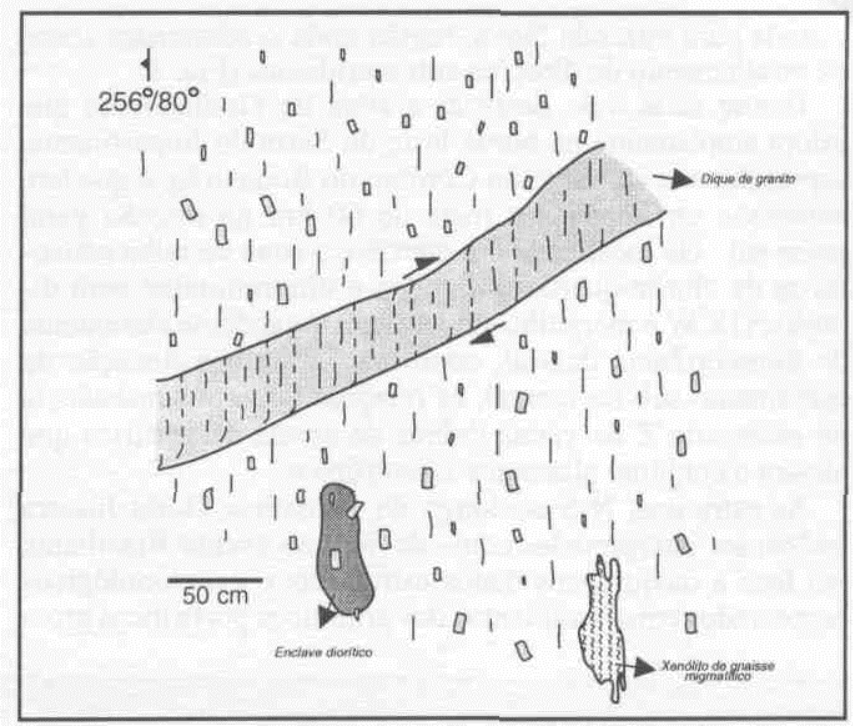

Figura 5 - Relações estruturais entre o GPG (granito porfirítico grosso) e dique granítico. A foliação magmática é marcada pêlos megacristais euédricos de K-feldspato, sendo paralela à foliação tectônica marcada por biotita. A foliação tectônica atravessa também o dique de granito sub-verticai

Figure 5 - Structural relationships between the GPG (coarse-grained porphyritic granite) and the granite dyke. The magmatic foliation is defmed by the euhedral K-feldspar megacrysts and is parallel to the tectonic foliation, marked by biotite crystals. The tectonic foliation is also present in the sub-vertical granite dyke.

As amostras são colocadas em filamentos de $\mathrm{Ta}$, com $\mathrm{F}^{\wedge} \mathrm{O}$ e H3PÜ4, sendo as análises feitas em um espectrômetro de massa do tipo VG Micromass 30. Os erros 2a são menores que $0,02 \%$ nas razões ${ }^{87} \mathrm{Sr} /{ }^{86} \mathrm{Sr}$. As razões ${ }^{87} \mathrm{Rb} /{ }^{86} \mathrm{Sr}$ foram obtidas a partir de determinações de $\mathrm{Rb}$ e $\mathrm{Sr}$ efetuadas por Fluorescência de Raios-X. Erros menores que 2\% são estimados para essas determinações.

A amostragem dos diversos litotipos foi feita visando um maior controle quanto à cogeneticidade do material. Para tanto, optou-se pela coleta de amostras em um mesmo afloramento, o qual possuísse dimensões suficientes para uma amostragem significativa. Tal procedimento, apesar de garantir essa premissa, gera uma variação muito pequena na razão ${ }^{87} \mathrm{Rb} /{ }^{86} \mathrm{Sr}$ no lote de amostras coletado. Assim, o espalhamento dos pontos na isócrona é pequeno, o que torna grandes os erros obtidos para as idades Rb-Sr. Essa é a principal razão para os altos valores dos erros nas idades, encontrados neste estudo. Todos esses erros são indicados dentro do intervalo de confiança de $95 \%$.

As análises isotópicas foram realizadas no Laboratório de Geocronologia da Universidade de Oxford, Inglaterra.

A determinação das concentrações de $\mathrm{Sm}$ e $\mathrm{Nd}$ foi feita por diluição isotópica, usando spikes de ${ }^{149} \mathrm{Sm}$ e ${ }^{150} \mathrm{Nd}$. O Sm é separado do Nd após a separação dos ETR a partir do pó da rocha, usando cromatografia de troca iônica.

Em bombas de teflon foram pesados $150 \mathrm{mg}$ de pó de rocha e $200 \mathrm{mg}$ de uma solução do spike misto. A dissolução das amostras foi feita em bomba vedada, a $150^{\circ} \mathrm{C}$, usando cerca de $5 \mathrm{ml}$ de $\mathrm{HF} 48 \%$ e $100 \mu \mathrm{l}$ de $\mathrm{HNO}_{3} 16 \mathrm{M}$, para dissolver as fases silicáticas. A solução foi então evaporada até secar, sendo submetida a um segundo ataque, idêntico ao primeiro, para a completa dissolução das fases resistentes. A solução foi então aquecida a $150^{\circ} \mathrm{C}$ por uma noite, ou períodos maiores, se fases resistentes estavam presentes. Após uma nova evaporação, ao resíduo foram adicionados $3 \mathrm{ml}$ de $\mathrm{HC} 16 \mathrm{~N} \mathrm{e} 2$ a $3 \mathrm{ml}$ 


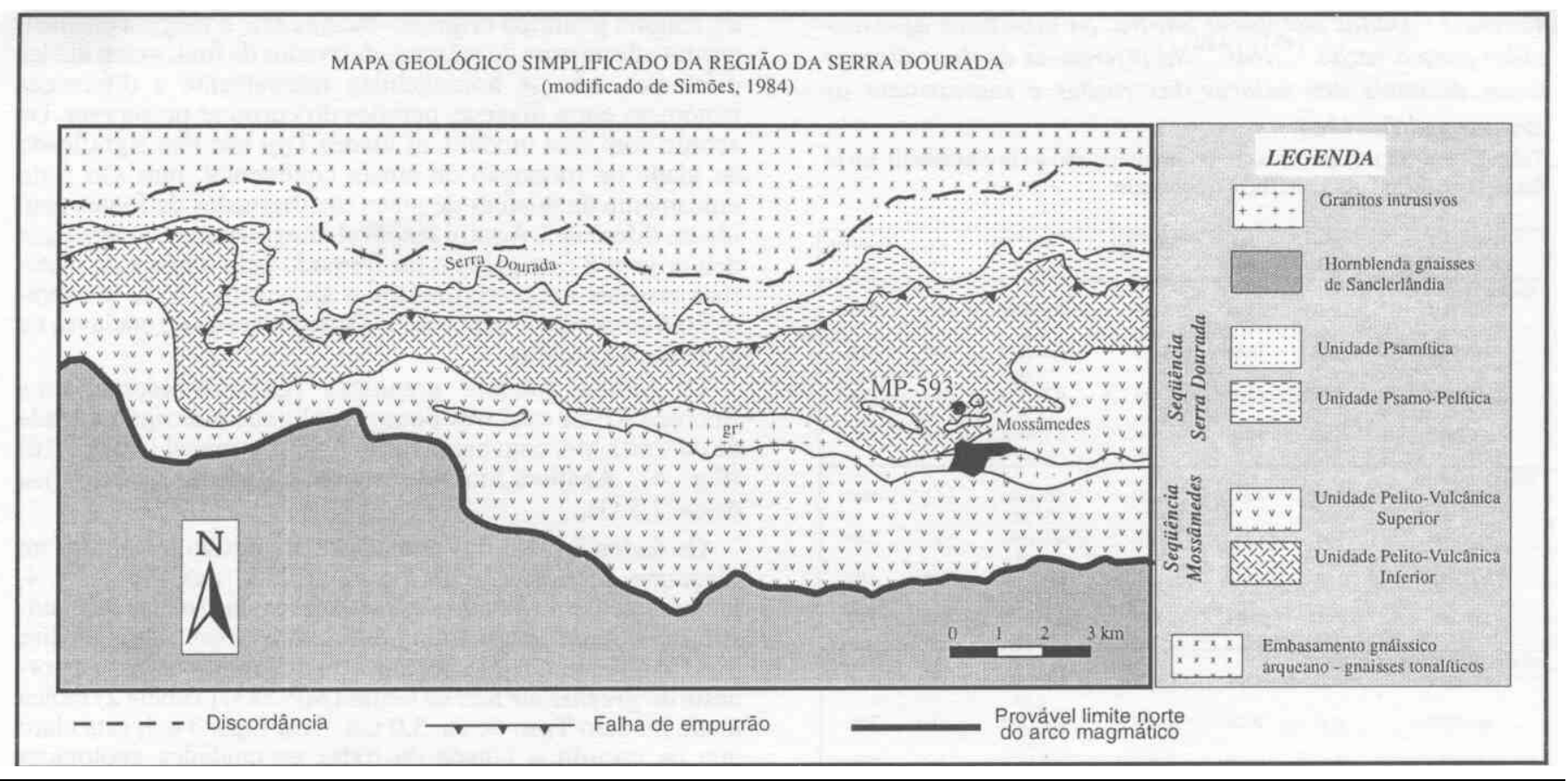

Figura 6 - Mapa geológico simplificado da região da Serra Dourada (Simões 1984).

Figure 6 - Geological map of the Serra Dourada region (Simões 1984).

de $\mathrm{H}_{3} \mathrm{BO}_{4}$, saturado em $\mathrm{HC1}$. Essa solução foi novamente aquecida a $150^{\circ} \mathrm{C}$, por algumas horas, sendo posteriormente evaporada até secar. $\mathrm{O}$ resíduo sofreu ataque com 2 a $2,5 \mathrm{ml}$ de $\mathrm{HC} 13 \mathrm{M}$, formando uma solução que foi então centrifugada.

A separação dos ETR foi feita em colunas de troca catiônica, com resina AG 50 X12, 200-400 mesh. Nas colunas, equilibradas com HC1 3M, foram colocados $2 \mathrm{ml}$ da soluçãoamostra, sendo lavadas duas vezes com $1 \mathrm{ml}$ de $\mathrm{HC} 13 \mathrm{M}$, e uma vez com $2 \mathrm{ml}$ do mesmo ácido. São passados então 20 $\mathrm{ml}$ de $\mathrm{HC} 1$, coletando-se apenas os $10 \mathrm{ml}$ finais, nos quais se encontra a fração de ETR. Essas frações foram coletadas em béqueres de teflon, sendo evaporadas até secar.

As frações de $\mathrm{Sm}$ e Nd foram obtidas a partir deste resíduo, por adição de $1 \mathrm{OO} \mu \mathrm{l}$ de $\mathrm{HC} 1(0,15 \mathrm{M})$. Essa solução foi deixada em repouso por algumas horas, sendo depois transferidos $\mathrm{O}, 1$ $\mathrm{ml}$ de amostra para colunas de ácido di-(2-etilexil)fosfórico (HDEHP), misturado a pó de teflon (PTFE). As colunas são previamente equilibradas com $\mathrm{HC} 10,15 \mathrm{M}$, e são lavadas por três vezes com $0,1 \mathrm{ml}$ de $\mathrm{HCl}$ e uma vez com $1 \mathrm{ml}$. Depois disso, são passados $14 \mathrm{ml}$ do mesmo ácido. A eluição das frações de $\mathrm{Nd}$ e Sm é feita com HC1 0,3M. A fração de Nd é obtida com a passagem de $3.5 \mathrm{ml}$ desse ácido, sendo desprezados os próximos 3,5 ml. São então coletados $9 \mathrm{ml} \mathrm{de}$ $\mathrm{HC1}$, nos quais se encontra a fração de Sm.

Em um arranjo triplo de filamentos, sendo o central de Re e os laterais de $\mathrm{Ta}$, as amostras de $\mathrm{Sm}$ e $\mathrm{Nd}$ foram depositadas nos filamentos laterais, usando $\mathrm{HNO}_{3} 1 \mathrm{M}$. As amostras foram analisadas usando um espectrômetro de massa VG Isomass $54 \mathrm{E}$, inteiramente automático. As análises tiveram precisão de $0.025 \%(2 \sigma)$ nos valores de Sm e Nd e um erro $2 \sigma \pm 0.000020$ na razão ${ }^{143} \mathrm{Nd} /{ }^{144} \mathrm{Nd}$. Essa razão foi normalizada com ${ }^{146} \mathrm{Nd} /{ }^{144} \mathrm{Nd}=0,7219$.

RESULTADOS E DISCUSSÕES Terrenos Gnáissicos Goiás-Jussara Sete amostras dos gnaisses tonalíticos (GT) expostos a oeste/sudoeste do greenstone belt de Goiás (Fig. 2) foram analisadas pelo método Rb-Sr (dados analíticos na Tabela 1). Os resultados originarei uma isócrona com idade $2564 \pm 140 \mathrm{Ma}$ e baixa razão ${ }^{87} \mathrm{Sr} /{ }^{86} \mathrm{Sr}$
Tabela $l$ - Dados isotópicos Rb-Sr. As incertezas (2o-desvio padrão) na razão isotópica ${ }^{87} \mathrm{Sr} /{ }^{86} \mathrm{Sr}$ estão na quinta casa decimal, representadas pelo algarismo após o valor da razão. Table 1 - Rb-Sr isotopic data. $2 \sigma$ uncertainties shown in parenthesis are in the last two digital places of the isotopic ratio.

\begin{tabular}{|c|c|c|c|c|}
\hline AMOSTRA & $\mathrm{Rb}(\mathrm{ppm})$ & $\mathrm{Sr}(\mathrm{ppm})$ & ${ }^{87} \mathrm{Rb} /{ }^{86} \mathrm{Sr}$ & ${ }^{87} \mathrm{Sr} /{ }^{86} \mathrm{Sr}$ \\
\hline \multicolumn{5}{|c|}{ Gnaisse Uvá (GT) } \\
\hline MP-581C & 33 & 348 & 0.277 & $0.71171 \pm 5$ \\
\hline MP-581I & 20 & 365 & 0.157 & $0.70815 \pm 4$ \\
\hline MP-58IA & 17 & 764 & 0.066 & $0.70405 \pm 6$ \\
\hline MP-581H & 31 & 351 & 0.254 & $0.71089 \pm 4$ \\
\hline MP-581F & 20 & 711 & 0.082 & $0.70467 \pm 5$ \\
\hline MP-58IE & 18 & 706 & 0.075 & $0.70438 \pm 4$ \\
\hline MP-581B & 10 & 736 & 0.039 & $0.70318 \pm 5$ \\
\hline \multicolumn{5}{|c|}{ Granito porfirítico (GPG) } \\
\hline MP-574A & 56 & 899 & 0.179 & $0.70722 \pm 5$ \\
\hline MP-574B & 68 & 802 & 0.246 & $0.70782 \pm 5$ \\
\hline MP-574C & 55 & 878 & 0.181 & $0.70724 \pm 4$ \\
\hline MP-575A & 93 & 714 & 0.376 & $0.70936 \pm 6$ \\
\hline MP-575B & 52 & 961 & 0.157 & $0.70695 \pm 5$ \\
\hline \multicolumn{5}{|c|}{ Granito gnaisse (GG) } \\
\hline MP- $573 \mathrm{~A}$ & 67 & 612 & 0.316 & $0.71332 \pm 5$ \\
\hline MP-573B & 68 & 562 & 0.351 & $0.71492 \pm 5$ \\
\hline MP-576 & 49 & 1224 & 0.115 & $0.70590 \pm 5$ \\
\hline \multicolumn{5}{|c|}{ Sequiência Mossâmedes } \\
\hline MP-593D & 65 & 477 & 0.395 & $0.71401 \pm 5$ \\
\hline MP-593F & 64 & 441 & 0.420 & $0.71403 \pm 6$ \\
\hline MP-593K & 62 & 246 & 0.730 & $0.72208 \pm 5$ \\
\hline MP-593H & 70 & 205 & 0.990 & $0.73151 \pm 7$ \\
\hline MP-593Q & 92 & 120 & 2.228 & $0.76455 \pm 4$ \\
\hline MP-593P & 94 & 119 & 2.305 & $0.76651 \pm 5$ \\
\hline MP- $593 \mathrm{~N}$ & 96 & 109 & 2.566 & $0.77500 \pm 5$ \\
\hline MP-593M & 155 & 160 & 2.830 & $0.78604 \pm 6$ \\
\hline MP-592B & 7 & 1623 & 0.012 & $0.70590 \pm 6$ \\
\hline MP-592C & 106 & 187 & 1.646 & $0.74500 \pm 7$ \\
\hline MP-592E & 125 & 715 & 0.506 & $0.71599 \pm 4$ \\
\hline MP-592A & 106 & 580 & 0.529 & $0.71681 \pm 7$ \\
\hline
\end{tabular}


Tabela 2 - Dados isotópicos Sm-Nd. As incertezas apresentadas para a razão ${ }^{143} \mathrm{Nd} /{ }^{144} \mathrm{Nd}$ referem-se às duas últimas casas decimais dos valores das razões e representam os desvios padrões $(2 \sigma)$.

Table 2 - Sm-Nd isotopic data. $2 \sigma$ uncertainties shown in parenthesis are in the last two digital places of the isotopic ratio.

\begin{tabular}{|c|c|c|c|c|c|c|}
\hline Amusira & $\underset{\text { Sm }}{\mathrm{Smpm})}$ & $\begin{array}{c}\mathrm{Nd} \\
(\mathrm{ppmi})\end{array}$ & 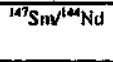 & ${ }^{14} \mathrm{Nd} d^{14} \mathrm{Nd}$ & $\begin{array}{l}E_{\mathrm{X}} \\
(\mathbf{T})\end{array}$ & $T_{D_{M}\left(G_{2}\right)}$ \\
\hline $\begin{array}{c}\text { Gnaisse unalítiou Uvá (GT } \\
\text { MP-5RII }\end{array}$ & 2.63 & 13.85 & 0.115 & $\begin{array}{c}0.51(0942 \\
\pm 19\end{array}$ & -5.8 & 3.27 \\
\hline MP-58IF & 2.65 & 14.55 & 0.110 & $\begin{array}{c}0.510963 \\
\pm 16\end{array}$ & -3.7 & 3.08 \\
\hline MP-581G & 2.61 & 13.59 & 0.116 & $\begin{array}{c}0.511095 \\
\pm 20\end{array}$ & -3.1 & 3.06 \\
\hline MP-581B & 2.87 & 14.03 & 0.124 & $\begin{array}{c}0.5109995 \\
\pm 23\end{array}$ & $.7 . k$ & 3,51 \\
\hline $\begin{array}{c}\text { Ganito Uvá (GU) } \\
\text { MP-578A }\end{array}$ & 0.438 & 1.974 & 0.1343 & $\begin{array}{l}10.511486 \\
\pm 20\end{array}$ & -1.7 & 3.00 \\
\hline MP-579A & 0.237 & 1.297 & $0.110 \%$ & $\begin{array}{l}0.511030 \\
\pm 24\end{array}$ & -4.7 & 2.99 \\
\hline MP.578D & 0.655 & 2.912 & 0.136 & $\begin{array}{c}0.511513 \\
\pm 20\end{array}$ & -1.8 & 3.02 \\
\hline MP578E & 0.461 & $2.08 i$ & 0.134 & $\begin{array}{r}0.511446 \\
\quad \pm 18 \\
\end{array}$ & -1.8 & 3.07 \\
\hline $\begin{array}{l}\text { Granito porfirilicu (GPG) } \\
\text { MP-574A }\end{array}$ & 4.45 & 30.01 & 0.090 & $\begin{array}{c}0.511284 \\
\pm 211\end{array}$ & $-1\left(\kappa_{0} .0\right)$ & 2.14 \\
\hline MP-574C & 4.16 & 28.06 & 0.089 & $\begin{array}{c}0.511235 \\
\pm 19\end{array}$ & -17.0 & 2,21 \\
\hline MP-575A & 3.00 & 20.88 & 0.087 & $\begin{array}{l}0.5+1130 \\
\pm 17\end{array}$ & $-19,0$ & 2.29 \\
\hline MP-575B & 3.73 & 27.68 & 0.081 & $\begin{array}{c}0.511313 \\
\pm 19\end{array}$ & -14.6 & $1.9 \%$ \\
\hline $\begin{array}{c}\text { Granititg gnaisse (GG) } \\
\text { MP-573A }\end{array}$ & 5.17 & 38.04 & $0.0 \% 2$ & $\begin{array}{l}0.51040 \mathrm{~KB} \\
\pm 21\end{array}$ & +4.6 & 2.47 \\
\hline MP-573B & 4,43 & 30.33 & 0.146 & $\begin{array}{c}0.510958 \\
\pm 19\end{array}$ & - & 2.50 \\
\hline MP-576 & 3,24 & 23,69 & $0.0 \times 4$ & $\begin{array}{c}0.510 \% 90 \\
\pm 21 \\
\end{array}$ & +5.3 & 2.42 \\
\hline $\begin{array}{l}\text { Sequencia Mosstimedes } \\
\text { MP-593E }\end{array}$ & 11.72 & 72.7 & 0.097 & $\begin{array}{c}0.511353 \\
\pm 24\end{array}$ & +0.5 & $2.2 \mathrm{t}$ \\
\hline MPP-5Y31 & 10.78 & 66.3 & 0.098 & $\begin{array}{c}0.511 .350 \\
\pm 20\end{array}$ & +0.5 & 2.2 .3 \\
\hline $\begin{array}{c}\text { Gnaisse de Guifís } \\
\text { MP-5R3F }\end{array}$ & 2.73 & 18.46 & $0.06 \%$ & $\begin{array}{c}0.510560 \\
\pm 19 \\
\end{array}$ & - & 3,03 \\
\hline
\end{tabular}

inicial $(0,7017 \pm 0,0003)$ (Fig. 3). Os resultados analíticos pelo método Sm-Nd para quatro amostras desses gnaisses indicaram uma larga faixa de valores de idades modelo $\mathrm{T}_{\mathrm{DM}}$ (DePaolo, 1980), entre ca. 3,0 e 3,5 Ga (Tabela 2). Valores de $\varepsilon_{\mathrm{Nd}}(\mathrm{T}=2,5 \mathrm{Ga})$ são negativos, entre $-4,4$ e $-8,8$ (Fig. 3). Esses resultados sugerem que a isócrona $\mathrm{Rb}-\mathrm{Sr}$, apesar de mostrar um baixo valor da razão inicial, indica uma idade que mais provavelmente representa re-homogeneização isotópica, talvez por metamorfismo sobre rochas mais antigas. A grande variação nos valores de $\mathrm{T}_{\mathrm{DM}}$ é função da variação das razões $\mathrm{Sm} / \mathrm{Nd}$, causada provavelmente por metamorfismo.

O biotita granito exposto nas vizinhanças de Uvá (GU) (Fig. 3) foi analisado pelo método Sm-Nd. As análises de quatro amostras resultaram em uma isócrona indicando a idade de $2851 \pm 180 \mathrm{Ma}$ e $\varepsilon_{\mathrm{Nd}}(\mathrm{T}=2.8 \mathrm{Ga})$ ) de $+0,3$ (Figura 3). Idades modelo $\mathrm{T}_{\mathrm{DM}}$ variam entre ca. 2,8 e $2,9 \mathrm{Ga}$. A idade de ca. 2,9 Ga para esse granito deve representar uma idade próxima à época de extração do material original do manto.

Amostras do corpo de granito porfirítico que aflora a oeste de Itapirapuã foram datadas através de uma isócrona $\mathrm{Rb}-\mathrm{Sr}$ em rocha total com cinco pontos (Fig. 4). A isócrona revelou a idade de $759 \pm 62$ Ma e razão inicial de 0,7053 $\pm 0,0002$. Análises Sm-Nd desse granito

indicam que o magma granítico original foi derivado de material crustal mais antigo. Idades modelo TDM estão entre ca. 2,0 e 2,4 Ga. Nesse caso, a grande variação nos valores de $\mathrm{T}_{\mathrm{DM}}$ não está relacionada com diferenças nas razões

$\mathrm{Sm} /{ }^{1} \mathrm{Nd}$ entre as amostras, mas sim com os diferentes valores de $\varepsilon_{\mathrm{Nd}}(\mathrm{T})$ que estão aproximadamente entre $-13,0 \mathrm{e}$ $-20,0$ (Fig. 4). Esse padrão é consistente com heterogeneidade do magma granítico original. Nesse caso, o magma original, produto da mistura de magmas derivados de fontes com idades diferentes, não se homogeiniza inteiramente e diferenças isotópicas entre diversas porções do corpo se preservam. De acordo com esse modelo, as idades $\mathrm{T}_{\mathrm{DM}}$ não têm significado de idade de formação de crosta continental, mas são fruto unicamente da mistura de materiais derivados de fontes com idades diferentes. Aqui, é razoável imaginar que o magma que deu origem a esse granito foi formado pela mistura de materiais crustais neoproterozóicos e arqueanos. Essa interpretação é consistente com a abundante presença de enclaves de gnaisses no granito.

Os biotita gnaisses graníticos (GG) forneceram uma isócrona $\mathrm{Rb}-\mathrm{Sr}$ com três pontos analíticos indicando a idade de ca. $2601 \mathrm{Ma}$, com baixa razão ${ }^{87} \mathrm{Sr} /{ }^{86} \mathrm{Sr}$ inicial (ca. 0,7016) (Fig. 4). Análises Sm-Nd resultam em idades modelo $\mathrm{T}_{\mathrm{DM}}$ de ca. 2,5 Ga.

Os dados Sm-Nd das unidades acima estão mostrados no diagrama de evolução isotópica de $\mathrm{Nd}$ das Figs. 3 e 4, juntamente com a composição isotópica das rochas que constituem o Arco Magmático de Goiás, a oeste. Uma análise $\mathrm{Sm}-\mathrm{Nd}$ adicional para uma amostra de granito-gnaisse a nordeste do greenstone belt de Goiás (MP-583) (Tabela 2) indica idade modelo $\mathrm{T}_{\mathrm{DM}}$ de ca. 3,0 Ga. Nas Figs. 3 e 4, está claro que os protolitos ígneos de todas as unidades geológicas investigadas se formaram no arqueano ou, no caso do GPG, incorporaram proporções substanciais de material crustal antigo quando da sua formação no Neoproterozóico.

Região de Mossâmedes As rochas metavulcânicas da Unidade Pelito-Vulcânica Inferior na região de Mossâmedes (Fig. 6) foram investigadas e oito amostras do afloramento MP-593 definiram a isócrona $\mathrm{Rb}-\mathrm{Sr}$ em rocha total da Fig. 7. A idade é de $1977 \pm 55$ Ma e a razão inicial ${ }^{87} \mathrm{Sr} /{ }^{86} \mathrm{Sr}$ é baixa $(0,7023 \pm 0,0003)$, sugerindo curta residência crustal do protolito. O mesmo é indicado pelas análises Sm-Nd de duas dessas amostras (Tabela 2). Elas indicam valores de $\mathrm{T}_{\mathrm{DM}}$ de ca. 2,2 Ga, um pouco mais velhas que a idade isocrônica $\mathrm{Rb}$-Sr. Rochas metavulcânicas expostas em outro afloramento da Unidade Pelito-Vulcânica Inferior, situado a cerca de $6 \mathrm{~km}$ a leste do ponto MP-583, também foram amostradas. As análises $\mathrm{Rb}-\mathrm{Sr}$ resultaram em uma isócrona com quatro pontos indicando uma idade mais jovem (1582 \pm $101 \mathrm{Ma}$ ) e razão inicial mais elevada (ca. 0.7053), podendo estar indicando um evento de re-homogeneização isotópica do sistema $\mathrm{Rb}$-Sr durante o Mesoproterozóico. Assim, essas rochas, apesar de apresentar assinatura geoquímica de arco vulcânico (Simões, 1984), não integram o arco magmático de Goiás. Elas tampouco fazem parte do Grupo Araxá, o que é consistente com as interpretações de Danni et al (1973) e Barbosa (1985). Dessa forma, elas são melhor interpretadas como integrantes da extremidade sul do Maciço de Goiás. A idade deposicional das unidades psamítica e psamo-pelítica que sustentam a Serra Dourada continua desconhecida e permanece a possibilidade de que se trate de depósitos plataformais neoproterozóicos sedimentados na margem sul do Maciço de Goiás.

\section{CONCLUSÕES E POSSÍVEIS IMPLICAÇÕES PA-}

LEOGEOGRÁFICAS Os dados apresentados aqui permitem delinear as conclusões abaixo:

(i) As unidades GT e GU, na região entre Goiás e Uvá são de idade arqueana. Idades modelo TDM estão, na maioria, entre 3,0 e 3,3 Ga e sugerem, juntamente com a TDM para a amostra do granito-gnaisse a nordeste do greenstone belt de Goiás, evento de adição crustal nessa época. Essas unidades foram somente fracamente afetadas pela deformação NS, de idade neoproterozóica. 


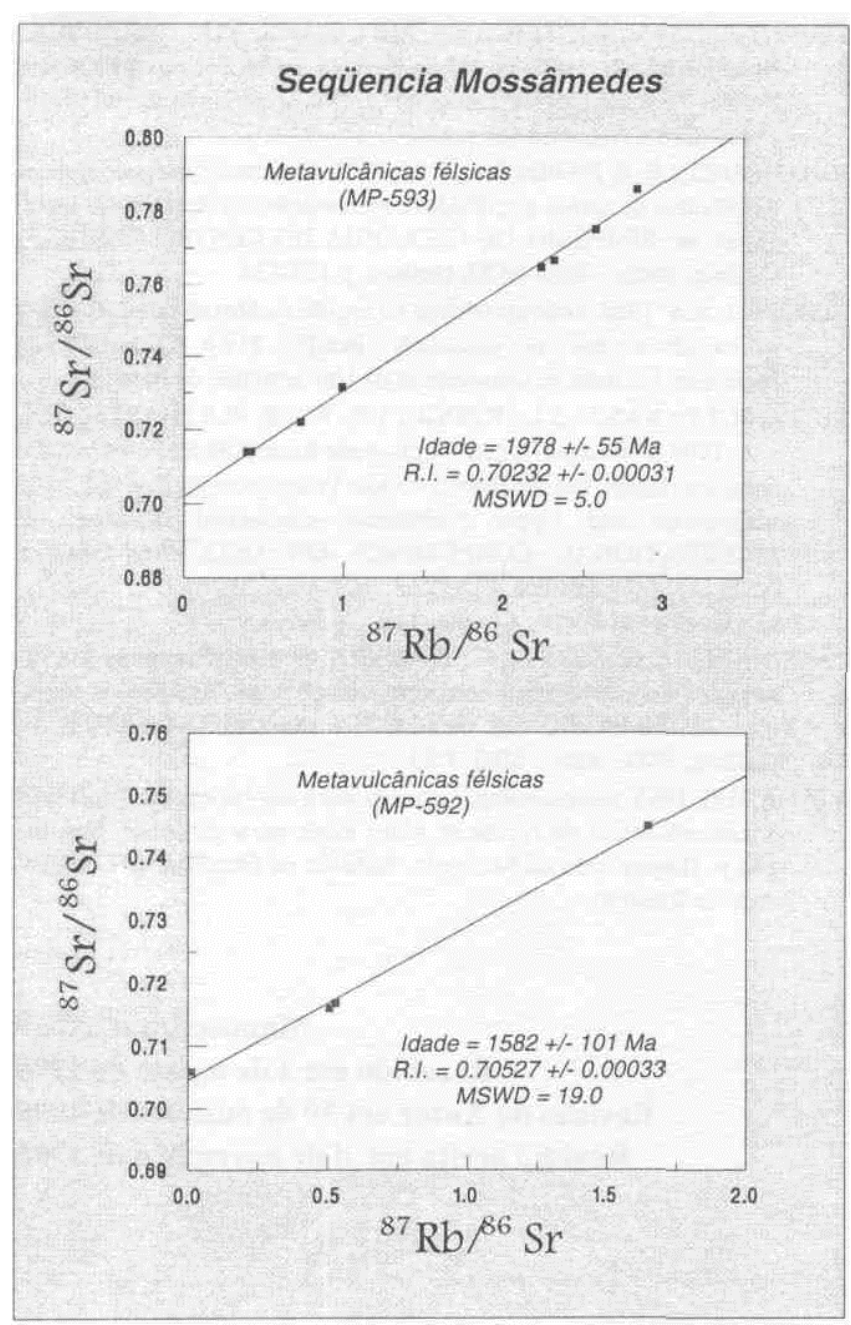

Figura 7 - Isócronas Rb-Sr de rochas metavulcânicas felsicas da Unidade Pelito-Vulcânica Inferior da Sequência Mossâmedes.

Figure 7 - Rb-Sr isochrons for felsic metavolcanic rocks of the Lower Pelitic-Volcanic Unit of the Mossâmedes Sequence.

(ii) As rochas da unidade GM mostram forte foliação milonítica com direção entre N30E e N10W, que indica deslocamentos dextrais de natureza direcional. Essa deformação é mais provavelmente de idade Neoproterozóica, e torna-se progressivamente mais importante em direção a oeste;

(iii) O GPG foi intrudido há ca. de $759 \mathrm{Ma}$, sintectonicamente, e o magma granítico original representa o produto de refusão de crosta continental mais antiga (paleoproterozóica ou arqueana) ou de mistura de materiais derivados da refusão de fontes crustais neoproterozóicas e arqueanas. A idade do granito representa uma boa estimativa para a época do cisalhamento NS, em relação a qual ele é sintectônico. Essa idade de ca. $760 \mathrm{Ma}$ é semelhante a idades metamórficas

\section{REFERENCIAS}

BARBOSA, P.A.R. 1985. Geologia e recursos minerais das sequências supracrustais a leste de Mossâmedes - GO. Brasília, 226 p. (Dissertação de mestrado., Instituto de Geociências da Universidade de Brasília).

BARBOSA. P.A.R. e JOST, H. 1990. Caracterização das sequências supracrustais precambrianas a leste de, Mossâmedes, Go. SBG, XXXVI Congr.Bras. Geol., Anuis..., 1:1-16

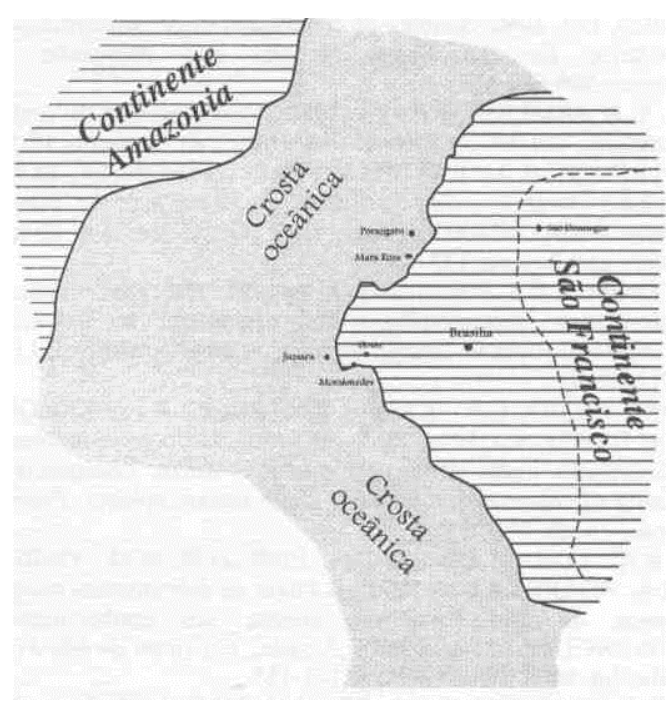

Figura 8 - Provável configuração da borda oeste da placa do São Francisco-Congo durante o Neoproterozóico. Limite aproximado do Cráton do São Francisco está mostrado pela linha tracejada.

Figure 8 - Probable configuration of the western margin of the São Francisco-Congo plate during the Neoproterozoic. The western border of the São Francisco Cráton is represented by the dotted line.

recentemente verificadas em outras áreas de Goiás (Pimentel et al. 1992, Ferreira $\mathrm{F}^{-}$et al. 1994, Suita et al. 1994);

(iv) Na região de Mossâmedes, as rochas metavulcânicas estudadas são do Paleoproterozóico e integram a extremidade sul do Maciço de Goiás. Poucos quilómetros a sul da exposição dessas rochas metavulcânicas estão os ortognaisses neoproterozóicos de Sanclerlândia, constituintes do Arco Magmático de Goiás. Assim, nessa área, o limite entre o Maciço de Goiás e o Arco Magmático é provavelmente representado pelo contato entre os gnaisses Sanclerlândia e as rochas supracrustais das unidades pelito-vulcânicas da Sequência Mossâmedes (Fig. 3).

Todas as unidades geológicas investigadas fazem parte do Maciço de Goiás, cujos limites oeste e sul correspondem, respectivamente, à zona de cisalhamento situada a aproximadamente $15 \mathrm{~km}$ a leste de Jussara, e ao contato entre a Sequência Mossâmedes e os gnaisses Sanclerlândia (Fig. 6). Esses dados permitem, portanto, delinear preliminarmente os limites da parte sul do Maciço de Goiás. Pode-se especular, como mostrado na Fig. 8, que esse limite corresponda ao limite paleogeográfico original entre a borda oeste do continente neoproterozóico São Francisco/Congo e o oceano existente entre ele e o Cráton Amazônico. De acordo com essa interpretação, o Maciço de Goiás representa a extremidade ocidental daquele continente, e teria atuado como uma saliência indentadora durante a colisão das duas massas continentais.

Agradecimentos Os autores agradecem ao $\mathrm{CNPq}$ pelo apoio financeiro (Proc. 53.0299/93-3)

DANNI, J.C.M.; FUCK, R.A.; RIBEIRO, M.J. 1973. Geologia da extremidade sudoeste da Serra Dourada (Goiás, Brasil). Revista Brasileira de Geociências, 3:160-180

DARDENNE, M.A.; DANNI, J.C.M.; FUCK, R.A. 1981. Revisão estratigráfica do Grupo Araxá na região da Serra Dourada, GO. In: SIMPÓSIO DE GEOLOGIA DO CENTRO-OESTE, 1., Goiânia, 19\%।, Anais... Goiânia, SBG, p.664-681. 
DE PAOLO, D. J. 1980. Sources of continental crust: neodymium isotope evidence for the Sierra Nevada and Peninsular Ranges. Science,209:6\&4-681.

HASUI, Y. \& ALMEIDA, F.F.M.de 1970.' Geocronologia do centro-oeste brasileiro: Boletim da Sociedade Brasileira de Geologia, 19:5-26.

JOST, H; FUCK, R A ; BARBOSA, P A R e PIMENTEL, M M. 1986. Estudos estruturais sobre o lineamento Messianópolis_Novo Brasil, Goiás - SBG, XXXIV Congr. Brás. Geol., Goiânia, Resumo das Comunicacões, pg. : 137

KARLSTROM, K.E \& WILLIAMS, M.L. 1995. The case for simultaneous deformation, metamorphism and plutonism: an example from Proterozoic rocks in central Arizona. Journal ofStructural Geology,

FERREIRA FILHO, C.F.; KAMO, S.L.; FUCK, R.A.; KROGH, T.E.; NALDRETT, A.J. 1994. Zircon and rutile U-Pb geochronology of the Niquelândia mafic-ultramafic intrusion, Brazil: constraints for the timing of magmatism and high-grade metamorphism. Precambrian Research, 68:241-255.

FUCK, R.A.; JARDIM DE SÁ, E.F.; PIMENTEL.M.M.; DARDENNE, M. A.; SOARES.A.C.P. 1993. As faixas de dobramentos marginais do Cráton do São Francisco; síntese dos conhecimentos. In: DOMINGUEZ,J.M.L. \& MISI.A.. eds., O Cráton do São Francisco, Salvador, SBG-SGM-CNPq, p. 161 -185.

FUCK, R. A.; PIMENTEL, M.M.; SILVA, L.J.H.D. 1994. Compartimentação tectônica da porção oriental da Província Tocantins. In: CONGRESSO BRASILEIRO DE GEOLOGIA, 38., Balneário Camboriú, 1994, Boletim de Resumos Expand., Camboriú, SBG, 1:215-216.

PIMENTEL, M.M. \& FUCK, R. A. 1992. Neoproterozoic crustal accretion in central Brazil. Geology, 20(4):375-379.

PIMENTEL, M.M; HEAMAN, L.; FUCK, R.A. 1991. U-Pb zircon and sphene geochronology of late Proterozoic volcanic are rock units from southwestern Goiás, Central Brazil. Journal of South American Earth Sciences , 4:329-339.

PIMENTEL, M.M.; WHITEHOUSE, M.J.; MACHADO, N.; FUCK, R.A.; VIANA, M.G. 1994. Neoproterozoic island are rocks of Mara Rosa, central Brazil: preliminary $\mathrm{U}-\mathrm{Pb}$ and $\mathrm{Sm}-\mathrm{Nd}$ data. In: INTERNATIONAL CONFERENCE ON GEOCHRONOLOGY AND COSMOCHRONOLOGY, 8., Berkeley, Abstracís..., Berkeley, U.S.Geological Survey Circular 1 107, p.252.
PIMENTEL, M.M.; WHITEHOUSE, M.J.; VIANA, M.G.; FUCK, R.A.; MACHADO, N. 1996. The Mara Rosa are in the Tocantins Province: Further evidence for Neoproterozoic crustal accretion in central Brazil. Precambrian Research (no preloj.

RODRIGUES, J.B. \& PIMENTEL, M.M. 1995. Características geoquímicas e isotópicas de rochas granitóides e metavulcânicas da região de Iporá, Goiás. In: SIMPÓSIO DE GEOLOGIA DO CENTRO-OESTE, 5., Goiânia, Anais... SBG-NCO, Goiânia, p.123-126.

SIMÕES, L.S.A 1984. O Grupo Araxá na região de Mossâmedes -Goiás, e as ocorrências minerais associadas. Brasília, 219 p. (Dissertação de Mestrado, Instituto de Geociências da Universidade de Brasília).

SUITA, M.T.F.; KAMO, S.L.; KROGH, T.E.; FYFE, W.S.; HARTMANN, L. A. 1994. U-Pb ages from the high-grade Barro Alto mafic-ultramafic complex (Goiás, central Brazil):middle Proterozoic continental mafic magmatism and Upper Proterozoic continental collision. In: INTERNATIONAL CONFERENCE ON GEOCHRONOLOGY AND COSMOCHRONOLOGY, 8., Berkeley, Abstracts..., Berkeley, U.S.Geological Survey Circular 1107, p.309.

TASSINARI, C.C.G.; SIGA Jr., O.; TEIXEIRA, W. 1981. Panorama geocronológico do centro-oeste brasileiro: soluções, problemática e sugestões, In: SIMPÓSIO DE GEOLOGIA DO CENTRO-OESTE, 1. Goiânia, 1981, Atas... SBG, 1:93

VIANA.M.G. 1995. Geocronologia e geoquímica das rochas ortognáissicas e metavulcânicas da região de Mara Rosa, norte de Goiás. Brasília, 110 p. (Dissertação de Mestrado, Instituto de Geociências Universidade de Brasília).
Manuscrito $\mathrm{n}^{\circ}$ ASSO

Recebido em 2 de agosto de 1996

Revisão do Autor em 30 de outubro de 1996 Revisão aceita em 4 de novembro de 1996 